TRIBUNAL DE JUSTIÇA DO ESTADO DA PARAÍBA Acórdão do processo $n^{\circ} 01720110000100001$

Órgão: Quarta Câmara Cível

Relator: Frederico Martinho da Nóbrega Coutinho Julgamento: 03/04/2012

MEIOS DE CONTROLE EM DIREITO SANITÁRIO. VIGILÂNCIA SANITÁRIA. LICENÇA DE FUNCIONAMENTO. DISTÂNCIA MÍNIMA. ART. 79, DA LEI ESTADUAL N ${ }^{\circ}$ 7.668/04. INCONSTITUCIONALIDADE INCIDENTAL. PRINCÍPIO DA LIVRE CONCORREANCIA. ENTENDIMENTO SUMULADO PELO SUPREMO TRIBUNAL FEDERAL. PRECEDENTES DESTA CORTE DE JUSTIÇA. - O limite geográfico resguardando-se a distância mínima de 500 (quinhentos) metros, contados a partir do estabelecimento com registro mais antigo no órgão de controle Sanitário Estadual viola e atinge o exercício da livre concorrência, sendo uma manifestação do princípio constitucional da liberdade de iniciativa econômica privada. - Mantém-se a decisão que concedeu a segurança, quando há a comprovação do direito líquido e certo da parte impetrante, negando-se provimento à Remessa Oficial.

\title{
COMENTÁRIO \\ DIREITO À SAÚDE, DIREITO À LIVRE CONCORRÊNCIA E AS LIMITAÇÕES TERRITORIAIS PARA A INSTALAÇÃO DE NOVOS ESTABELECIMENTOS COMERCIAIS
}

\author{
Right to health, right to free competition and \\ territorial limitations to establish new shops
}

Amanda Flávio de Oliveira*

Bruno Braz de Castro**

\footnotetext{
* Doutora, Mestre e Especialista em Direito Econômico, Universidade Federal de Minas Gerais. Diretora da Faculdade de Direito, Universidade Federal de Minas Gerais; Professora dos cursos de Graduação e Pós-Graduação da Faculdade de Direito, Universidade Federal de Minas Gerais. Advogada. Belo Horizonte/MG - Brasil. E-mail: amanda@afdeoliveira.com.br

** Mestre em Direito Econômico, Universidade Federal de Minas Gerais. Advogado. Belo Horizonte/MG - Brasil.
}

Artigo recebido em: 27/11/2012. Aprovado em: 30/11/2012. 


\title{
RESUMO
}

O princípio constitucional da livre concorrência, embora não compareça em nosso ordenamento jurídico como valor absoluto, é impassível de restrições irrazoáveis ou desproporcionais pela legislação infraconstitucional. O presente artigo analisa a decisão do Tribunal de Justiça do Estado da Paraíba nos autos da Remessa Oficial $n$. 017.2011.000010-0/001, que, reafirmando entendimento jurisprudencial já estabelecido, reconheceu a inconstitucionalidade da fixação de distância mínima para instalação de estabelecimentos farmacêuticos, com fundamento no princípio da livre concorrência.

Palavras-chave: Barreiras à Entrada; Direito da Concorrência; Direito à Saúde; Restrições Geográficas à Entrada.

\begin{abstract}
The free competition clause in the 1988 Brazilian Constitution, even though is not an absolute value, does not uphold unreasonable or disproportional restrictions on the competitive environment, even if those restrictions are promoted by a public legislation. This paper analyses the decision from the Paraíba State Court of Justice, in Remessa Oficial n. 017.2011.000010-0/001 that, confirming judicial precedents, declared that the regulation imposing geographic restrictions on entry on the relevant market for pharmacies is unconstitutional, for it is unreasonably anticompetitive.
\end{abstract}

Keywords: Competition Law; Entry Barriers; Geographic Restrictions on Entry; Public Health Law.

\section{A imposição legal de restrições territoriais à instalação de estabelecimentos comerciais e o Poder Judiciário}

Ao final da década de 1990, foi submetida à análise do Supremo Tribunal Federal (STF) a constitucionalidade de uma série de leis municipais que estabeleciam distância perimetral mínima para a instalação de estabelecimentos comerciais farmacêuticos na zona urbana. ${ }^{(1)}$

\footnotetext{
1 Em especial, nessas ocasiões foram debatidos o artigo $1^{\circ}$ da Lei Municipal $n^{\circ} 6.545 / 91$, de Campinas/SP: "A concessão de licença para instalação e funcionamento de drogarias e farmácias no Município de Campinas somente dar-se-á desde que não haja estabelecimento similar numa distância mínima de 500 (quinhentos) metros"; e o artigo $1^{\circ}$ da Lei Municipal n 10.991/91, de São Paulo/SP: "A licença de localização para a instalação de novas farmácias e drogarias no Município será concedida somente quando o estabelecimento ficar situado a uma distância mínima de 200 (duzentos) metros de raio da farmácia ou drogaria mais próxima já existentes".
} 
A legitimidade dos dispositivos em questão foi defendida com base em argumentos diversos, como: a competência do Município para legislar sobre assuntos de interesse local,(2) constituindo as leis mera disciplina da utilização do solo;(3) a segurança pública, uma vez que as farmácias armazenam produtos inflamáveis, cuja periculosidade seria ampliada pela proximidade dos estabelecimentos; ${ }^{(4)}$ e a ampliação do acesso de todas as camadas da população às farmácias, através de sua distribuição geográfica(5).

Os argumentos em sentido contrário, contudo, observavam que as legislações em questão eram ofensivas ao princípio da livre concorrência, haja vista viabilizarem a oferta exclusiva de produtos pelos comerciantes no perímetro em que a instalação de novos estabelecimentos seria proibida:

O que há é a redução dos espaços da concorrência, para que ela chegue ao consumidor e não o consumidor vá a ela. Essa é a distinção fundamental. É necessário assegurar que o consumidor - o objetivo final de toda a teoria da concorrência é assegurar preços baixos e produtos de boa qualidade - possa receber a concorrência dos comerciantes, e não ter que fazer a busca dessa concorrência. ${ }^{(6)}$

Com esteio nesse raciocínio, que se revelou majoritário, o STF reconheceu a inconstitucionalidade da regulação municipal de distância mínima entre estabelecimentos farmacêuticos. Esse entendimento culminou na edição da Súmula ${ }^{\circ} 646$ : "Ofende o princípio da livre concorrência lei municipal que impede a instalação de estabelecimentos comerciais do mesmo ramo em determinada área". ${ }^{(7)}$ A questão, no entanto, continua a gerar discussões judiciais em face de legislações análogas.

O acórdão analisado no presente trabalho ${ }^{(8)}$ discute a constitucionalidade do artigo $7^{\circ}$ da Lei Estadual $n^{\circ} 7.668 / 04$, da Paraíba, que estabelece que

[p]ara instalação de novos estabelecimentos farmacêuticos interessados ou não na comercialização dos produtos e dos serviços previstos nesta lei, deverá ser resguardada a distância mínima de 500 (quinhentos) metros, contados a partir do estabelecimento com registro mais antigo no órgão de controle Sanitário Estadual.

\footnotetext{
2 Art. 30. "Compete aos Municípios: I - legislar sobre assuntos de interesse local;". BRASIL. Constituição da República Federativa do Brasil de 1988. Disponível em: <http://www.planalto.gov. br/ccivil_03/constituicao/ConstituicaoCompilado.htm>. Acesso em: 19 jan. 2014.

${ }^{3}$ BRASIL. Supremo Tribunal Federal. RE 193.749-1-SP. Diário da Justiça da União, 04/05/2001, p. 3 (Voto Vencido do Ministro Carlos Velloso).

${ }^{4}$ BRASIL. Supremo Tribunal Federal. RE 199.517-3-SP. Diário da Justiça da União, 13/11/1998, p. 3. (Relatório do Ministro Carlos Velloso).

${ }^{5}$ BRASIL. Supremo Tribunal Federal. RE 193.749-1-SP. Diário da Justiça da União, cit. p. 2.

${ }^{6}$ BRASIL. Supremo Tribunal Federal. RE 193.749-1-SP. Diário da Justiça da União, 05/05/2001, p. 7. (Voto Ministro Nelson Jobim).

7 BRASIL. Supremo Tribunal Federal. Súmula n 646. Diário da Justiça da União, 09/10/2003.

8 BRASIL. Tribunal de Justiça do Estado da Paraíba. Acórdão para o processo Remessa Oficial - Mandado de Segurança n 017.2011.000010-0/001. Diário da Justiça do Estado da Paraíba, 10/04/2012, p. 14. (Relatório do Desembargador Frederico Martinho da Nóbrega Coutinho).
} 
O princípio constitucional da livre concorrência, conforme se verá, orienta, para o caso paraibano, a reafirmação do raciocínio jurídico expresso na Súmula STF n 646.

\section{Restrições territoriais à entrada e o direito concorrencial brasileiro}

As limitações contratuais ou legais à instalação de estabelecimentos comerciais em determinado território constituem importante objeto de preocupação do direito concorrencial brasileiro.

A lei antitruste brasileira (Lei $\left.n^{\circ} 12.529 / 11\right)^{(9)}$ reconhece ilicitude potencial às condutas de "acordar, combinar, manipular ou ajustar com concorrente, sob qualquer forma: (...) a divisão de partes ou segmentos de um mercado atual ou potencial de bens ou serviços, mediante, dentre outros, a distribuição de clientes, fornecedores, regiões ou períodos" e de "limitar ou impedir o acesso de novas empresas ao mercado", na medida em que tais condutas possuam a aptidão de provocar os efeitos estipulados no caput de seu artigo 36:

Art. 36. Constituem infração da ordem econômica, independentemente de culpa, os atos sob qualquer forma manifestados, que tenham por objeto ou possam produzir os seguintes efeitos, ainda que não sejam alcançados:

I - limitar, falsear ou de qualquer forma prejudicar a livre concorrência ou a livre iniciativa;

II - dominar mercado relevante de bens ou serviços;

III - aumentar arbitrariamente os lucros; e

IV - exercer de forma abusiva posição dominante.

O Conselho Administrativo de Defesa Econômica (CADE), tribunal administrativo responsável pela aplicação da lei, já teve a oportunidade de se manifestar acerca da análise concorrencial das restrições territoriais à instalação de empreendimentos, no âmbito dos procedimentos administrativos em que se discutiu a legalidade da estipulação contratual de "cláusula de raio" nos contratos de locação comercial em shopping centers paulistas. ${ }^{(10)}$

\footnotetext{
${ }^{9}$ BRASIL. Lei $n^{\circ}$ 12.529, de 30 de novembro de 2011. "Estrutura o Sistema Brasileiro de Defesa da Concorrência; dispõe sobre a prevenção e repressão às infrações contra a ordem econômica; altera a Lei $n^{\circ} 8.137$, de 27 de dezembro de 1990, o Decreto-Lei $n^{\circ} 3.689$, de 3 de outubro de 1941 - Código de Processo Penal, e a Lei $n^{\circ} 7.347$, de 24 de julho de 1985; revoga dispositivos da Lei no 8.884, de 11 de junho de 1994, e a Lei no 9.781, de 19 de janeiro de 1999; e dá outras providências.". Disponível em: <http://www.planalto.gov.br/ccivil_03/_ato2011-2014/2011/Lei/ L12529.htm>. Acesso em: 14. jan. 2014.

10 “...'cláusulas de raio' são aquelas pela quais o locatário de um espaço comercial se obriga, perante o locador, a não exercer atividade similar à praticada no imóvel objeto da locação em outro estabelecimento situado a um determinado raio de distância daquele imóvel.". BRASIL. Conselho Administrativo de Defesa Econômica. Processo Administrativo $n^{\circ}$ 1997.08012.006636, p.1. (Relatório do Conselheiro Luís Fernando Rigato Vasconcelos).
} 
$\mathrm{Na}$ ocasião, fixou-se o entendimento de que as restrições territoriais devem ser analisadas sob a "regra da razão" ou princípio da razoabilidade: analisam-se as circunstâncias concretas da prática econômica analisada, comparando-se seus potenciais benefícios (eficiências) e prejuízos à ordem econômica, de modo a apurar-lhes o efeito líquido para o bem-estar social:

Cláusula de Raio não é ilícita per se - Validade da Cláusula de Raio do ponto de vista concorrencial: quando adstrita a razoavelmente prevenir comportamentos oportunistas e garantir o retorno do investimento sem impor limites não razoáveis à concorrência no mercado relevante - Razoabilidade da cláusula a ser analisada em cada caso concreto - Inexistência de justificativas econômicas para o presente caso - Efeitos anticoncorrenciais da cláusula de exclusividade territorial caracterizados pela aplicação por tempo indeterminado, pelo modo de implementação e abrangência da cláusula, pelo fechamento de mercado e pela sua utilização para bloquear a diferenciação do concorrente - Infração tipificada pelo artigo 20, incisos I e IV c/c o artigo 21, inciso IV e V, da Lei $\mathrm{n}^{\circ} 8.884 / 94$. $^{(11)}$

Note-se que o caso em questão refere-se à imposição de restrições territoriais em contratos de direito privado. Adiante observaremos, contudo, que as exigências de proporcionalidade e razoabilidade mencionadas também se aplicam aos atos do Poder Público.

\section{Os direitos à saúde, à livre concorrência e a intervenção do estado no domínio econômico}

A intervenção normativa no domínio econômico ${ }^{(12)}$ é poder-dever constitucionalmente atribuído à União, Estados e Municípios. ${ }^{(13)} \mathrm{A}$ Constituição da República de 1988 (CF/88), contudo, não se presta a tão somente distribuir competências para a atuação estatal, mas igualmente fixa "diretrizes, programas e fins a serem implementados pelo Estado".(14)

Assim, ao promover a atuação do Estado no domínio econômico, deverá o legislador observar as diretrizes fixadas pela ordem econômica constitucional (constituição econômica), conjunto de princípios e regras através dos quais se

\footnotetext{
${ }^{11}$ BRASIL. Conselho Administrativo de DefesaEconômica. Processo Administrativon ${ }^{\circ} 08012.002841 / 2001$ 13, p. 1224. (Voto do Conselheiro Relator Roberto Augustos Castellanos Pfeiffer).

${ }^{12} \mathrm{~A}$ intervenção estatal normativa é aquela em que o poder público altera, direta ou indiretamente, o estatuto jurídico de determinada atividade econômica. SOUZA, Washington Peluso Albino de. Primeiras linhas de direito econômico. 6. ed. São Paulo: LTr, 2005. p. 245

${ }^{13}$ Art. 174: "Como agente normativo e regulador da atividade econômica, o Estado exercerá, na forma da lei, as funções de fiscalização, incentivo e planejamento, sendo este determinante para o setor público e indicativo para o setor privado". BRASIL. Constituição da República Federativa do Brasil de 1988, cit.

${ }^{14}$ GRAU, Eros. A Ordem Econômica na Constituição de 1988: interpretação e crítica. 12. ed. São Paulo: Malheiros Ed., 2007. p. 364.
} 
reconhecem "as bases para a política econômica a ser traduzida na legislação infraconstitucional". ${ }^{(15)}$

Muito embora a ordem econômica constitucional componha-se de uma série de normas jurídicas espalhadas ao longo de todo o texto da CF/88, alguns dos seus mais importantes enunciados encontram-se agrupados sob o Título VII, intitulado "Da Ordem Econômica e Financeira" (artigos 170 a 192).

Nesse conjunto normativo, é possível identificar as determinações de que a ordem econômica é fundada na "valorização do trabalho humano" e na "livre iniciativa", e tem por finalidade "assegurar a todos existência digna, conforme os ditames da justiça social" (artigo 170, caput), sendo orientada por alguns princípios, dentre eles a livre iniciativa (artigo 170, inciso I) e a livre concorrência (artigo 170, inciso IV), que, portanto, integram a matriz normativa a ser necessariamente observada pelo legislador ao intervir no domínio econômico.

Não basta, portanto, que o ente federativo possua competência para legislar sobre determinada matéria (como, no caso analisado, sustentou-se a constitucionalidade da lei em razão da competência do Município para regular assuntos de interesse local). ${ }^{(16)}$ É necessário que eventual prejuízo à ordem concorrencial decorrente de determinada legislação justifique-se no contexto da "ideologia constitucionalmente adotada."(17)

Soma-se a tudo isso, no caso em questão, a importante inovação conduzida pela CF/88, ao elevar o direito à saúde a direito fundamental. Agrava-se a situação quando, nas situações de limitação territorial para a instalação de novos estabelecimentos comerciais, encontra-se envolvido estabelecimento comercial destinado à garantia do acesso a esse direito. São os casos das drogarias, farmácias, entre outros, que constituem atividade comercial fundamental ao pleno exercício do direito individual à saúde.

A obstrução irrazoável ao pleno exercício de direitos fundamentais, que não se sustente em bases principiológicas e constitucionais sólidas, não pode encontrar guarida no ordenamento jurídico inaugurado com a CF/88. A necessidade de observância dos princípios constitucionais pelo legislador - e de sua ponderação, com vistas à máxima otimização de cada enunciado ${ }^{(18)}$ - leva à conclusão de que a legislação infraconstitucional que falhe em prestigiar os princípios constitucionais e os direitos humanos positivados, em desatenção aos critérios de

\footnotetext{
${ }^{15}$ SOUZA, Washington Peluso Albino de. Teoria da Constituição Econômica. Belo Horizonte: Del Rey, 2002. p. 23.

${ }^{16}$ BRASIL. Supremo Tribunal Federal. RE 193.749-1-SP. Diário da Justiça da União, 04/05/2001, cit. p. 3.

${ }^{17}$ Washington Peluso Albino de Souza define a "ideologia constitucionalmente adotada" como o "conjunto harmônico de princípios que vão inspirar a própria organização da vida social, segundo o regime que irá regê-la". SOUZA, Washington Albino Peluso de. Direito econômico. São Paulo: Saraiva, 1990. p. 33.

${ }^{18}$ Adota-se a construção teórica de Alexy. ALEXY, Robert. Teoria de los derechos fundamentales. Madrid: Centro de Estudios Constitucionales, 1993.
} 
proporcionalidade e de razoabilidade, encontra-se em desacordo com a CF/88 e assim deve ser declarado.

\section{Considerações Finais}

Sob as balizas mencionadas é que deve ser orientada a análise do impacto concorrencial da regulação de distância mínima entre estabelecimentos farmacêuticos.

Conforme observou o STF, os possíveis benefícios ao interesse público advindos das leis municipais revelaram-se francamente inferiores ao prejuízo concorrencial delas advindo. Daí decorre a conclusão de que as políticas econômicas municipais teriam vulnerado desproporcionalmente os princípios constitucionais da livre concorrência e da livre iniciativa e, portanto, não poderiam subsistir.

Na mesma linha, com acerto, posiciona-se o acórdão do Tribunal de Justiça do Estado da Paraíba. Com esteio na Súmula $n^{\circ} 646$ do Supremo Tribunal Federal, os julgadores reconheceram incidentalmente a inconstitucionalidade do artigo $7^{\circ}$ da Lei Estadual $n^{\circ} 7.668 / 04$ observando que "o limite geográfico (...) viola e atinge o exercício da livre concorrência, sendo uma manifestação do princípio constitucional da liberdade de iniciativa econômica privada".

No mesmo sentido, o parecer ministerial utilizado como fundamento para o acórdão destaca que "esse tipo de limitação não só é irrelevante para o fim a que se propõe como cria tanto para o interessado quanto para a própria população, na qualidade de consumidora, um limite impróprio e irrazoável de opção de mercado", haja vista que a intervenção estatal deve ser "mínima e estritamente necessária para a manutenção da ordem e exatamente para a viabilização da livre concorrência."(19)

Entende-se, portanto, que a atuação do poder público no domínio econômico não está isenta da observância ao princípio da livre concorrência, sendo perfeitamente cabível o controle de constitucionalidade dos atos normativos que ocasionem prejuízo desproporcional ou irrazoável à ordem concorrencial.

\section{Referências}

ALEXY, Robert. Teoria de los derechos fundamentales. Madrid: Centro de Estudios Constitucionales, 1993.

BRASIL. Conselho Administrativo de Defesa Econômica. Processo Administrativo $n^{\circ}$ 08012.002841/2001-13, p. 1224. (Voto do Conselheiro Relator Roberto Augustos Castellanos Pfeiffer).

\footnotetext{
${ }^{19}$ BRASIL. Tribunal de Justiça do Estado da Paraíba. Acórdão para o processo Remessa Oficial Mandado de Segurança N 017.2011.000010-0/001. Diário de Justiça do Estado da Paraíba, cit. p. 5. (Relatório do Desembargador Frederico Martinho da Nóbrega Coutinho).
} 
BRASIL. Conselho Administrativo de Defesa Econômica. Processo Administrativo $n^{\circ}$ 1997.08012.006636, p.1. (Relatório do Conselheiro Luís Fernando Rigato Vasconcelos).

Supremo Tribunal Federal. RE 193.749-1-SP. Diário da Justiça da União, 04/05/2001.

Supremo Tribunal Federal. RE 199.517-3-SP. Diário da Justiça da União, 13/11/1998. 09/10/2003.

Supremo Tribunal Federal. Súmula n 646. Diário da Justiça da União,

. Tribunal de Justiça do Estado da Paraíba. Acórdão para o processo Remessa Oficial - Mandado de Segurança № 017.2011.000010-0/001. Diário da Justiça do Estado da Paraíba, 10/04/2012.

GRAU, Eros. A Ordem Econômica na Constituição de 1988: interpretação e crítica. 12. ed. São Paulo: Malheiros Ed., 2007.

SOUZA, Washington Albino Peluso de. Direito econômico. São Paulo: Saraiva, 1990.

Primeiras linhas de direito econômico. 6. ed. São Paulo: LTr, 2005.

Teoria da Constituição Econômica. Belo Horizonte: Del Rey, 2002. 